\title{
Isolated acute pseudobulbar palsy with infarction of artery of percheron: case report and literature review
}

\author{
Jamir Pitton Rissardo, Ana Fornari Caprara
}

Federal University of Santa Maria, Santa Maria, Rio Grande do Sul, Brazil.

\begin{abstract}
Introduction: Pseudobulbar palsy (PBP) is characterized by supranuclear lesions in the corticobulbar pathway. Neoplasia, inflammatory, demyelinating, and stroke are possible etiologies of this disorder.

Case report: We report an elderly female who presented with dysarthria. She was dysarthric with a hypernasal voice, no apraxia or aphasia was observed. Tongue movements were slow with limited amplitude. Her soft palate dropped bilaterally; gag reflex was present. Also, she reported swallowing difficulty and choking with her saliva. Bilateral vertical and horizontal gaze were intact to either voluntary or oculocephalic movements. A cranial CT scan was suggestive of artery of Percheron (AOP) infarction. Brain magnetic resonance imaging showed hypersignal on diffusion-weighted and T2-weighted images and hyposignal on apparent diffusion coefficient in both thalami. CT angiography scan revealed an AOP originating from the left posterior cerebral artery. The swallowing study with a videofluoroscopic demonstrated oral and pharyngeal phases with severe dysfunction.

Conclusion: To the authors' knowledge, there are two cases of individuals with artery of Percheron infarction who developed PBP associated with other clinical syndromes. Still, isolated PBP following infarction of Percheron's artery was not reported. We hypothesized that the PBP may have occurred because of the existence of vascular territory variations in the perforating arteries that arise from the AOP.
\end{abstract}

Keywords: Pseudobulbar palsy; thalamus; infarction.

DOI: https://dx.doi.org/10.4314/ahs.v21i1.22

Cite as: Rissardo JP, Caprara AF. Isolated acute pseudobulbar palsy with infarction of artery of percheron: case report and literature review. Afri Health Sci. 2021;21(1):166-71. https:// dx.doi.org/10.4314/abs.v21i1.22

\section{Introduction}

Pseudobulbar palsy (PBP) is characterized by supranuclear lesions in the corticobulbar pathway. Neoplasia, inflammatory, and demyelinating diseases are possible etiologies of this disorder. In this context, another common cause of PBP are multiple and recurrent strokes. ${ }^{1}$ But, infarction of the diencephalon leading to dysarthria and dysphonia is rare.

There are only a few cases of bilateral paramedian thalamic infarction associated with acute pseudobulbar symptoms that have been reported in the literature. More specifically, to the authors' knowledge, there are two case reports of individuals with artery of Percheron (AOP) stroke who developed PBP associated with other clinical syndromes. ${ }^{2,3}$ Still, isolated PBP following infarction of Percheron's artery was not reported.

\section{Corresponding author: \\ Jamir Pitton Rissardo, \\ Federal University of Santa Maria, \\ Santa Maria, Rio Grande do Sul, Brazil. \\ Email: jamirrissardo@gmail.com}

Herein, we report a case of an adult female who developed isolated PBP secondary to infarction of AOP.

\section{Case report}

A 70-year-old female presenting with a difficult and unclear articulation of speech with sudden onset was admitted to our hospital. The individual was previously healthy, retired, and her family history was negative for neurological diseases. Her vital signs (blood pressure, heart rate, respiratory rate, temperature) were normal and stable.

On neurological examination, she was dysarthric with a hypernasal voice, no apraxia or aphasia was observed. Tongue movements were slow with limited amplitude and because of this it seemed that the tongue had difficulty moving, but when it was protruded no deviation occurred. Her soft palate dropped bilaterally; gag reflex was present. Also, she reported swallowing difficulty and choking with her saliva. Bilateral vertical and horizontal gaze were intact to either voluntary or oculocephalic movements. Palpebral oculogyric reflex was normal. Myosis, ptosis, nystagmus, and skew deviation were not present. On the National Institutes of Health 
Stroke Scale (NIHSS), she only scored in dysarthria, which was characterized by unintelligible slurring or out of proportion to dysphasia.

Laboratory blood tests and urinalysis were within normal limits. A cranial computed tomography (CT) scan at the symptoms' onset (Figure $1-\mathrm{A}, \mathrm{D}$ ) and two days after (Figure 1- B, C, E, F) was suggestive of infarction of Percheron's artery. Brain magnetic resonance imaging showed hypersignal on diffusion-weighted and T2-weighted images and hyposignal on apparent diffusion coefficient in both thalami regions. CT angiography scan revealed an artery of Percheron originating from the left posterior cerebral artery, which was impaired. The cerebral spinal fluid analysis was normal; culture was negative. The swallowing study with a videofluoroscopic demonstrated oral and pharyngeal phases with severe dysfunction. The patient was referred to another hospital and the follow-up was lost.
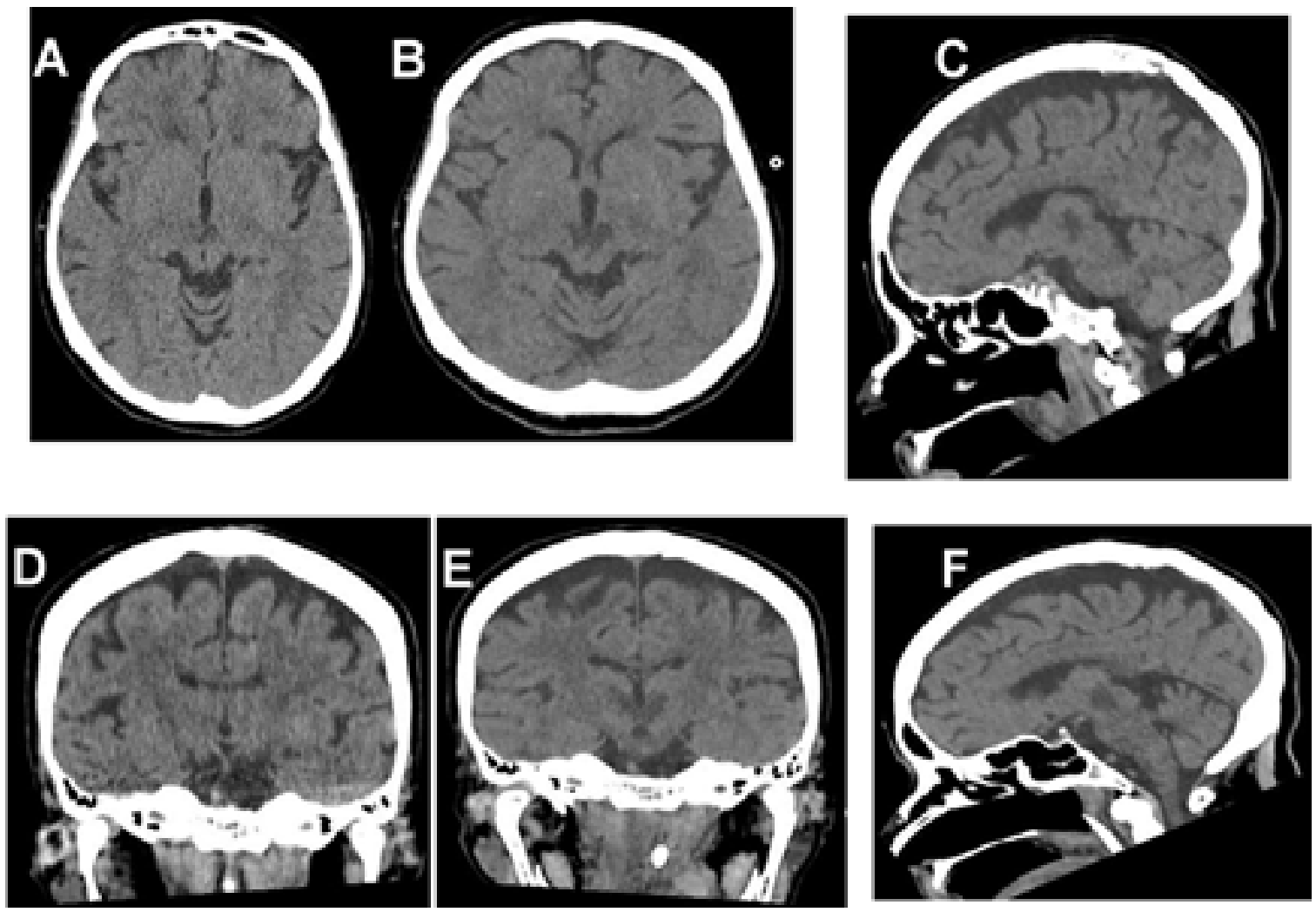


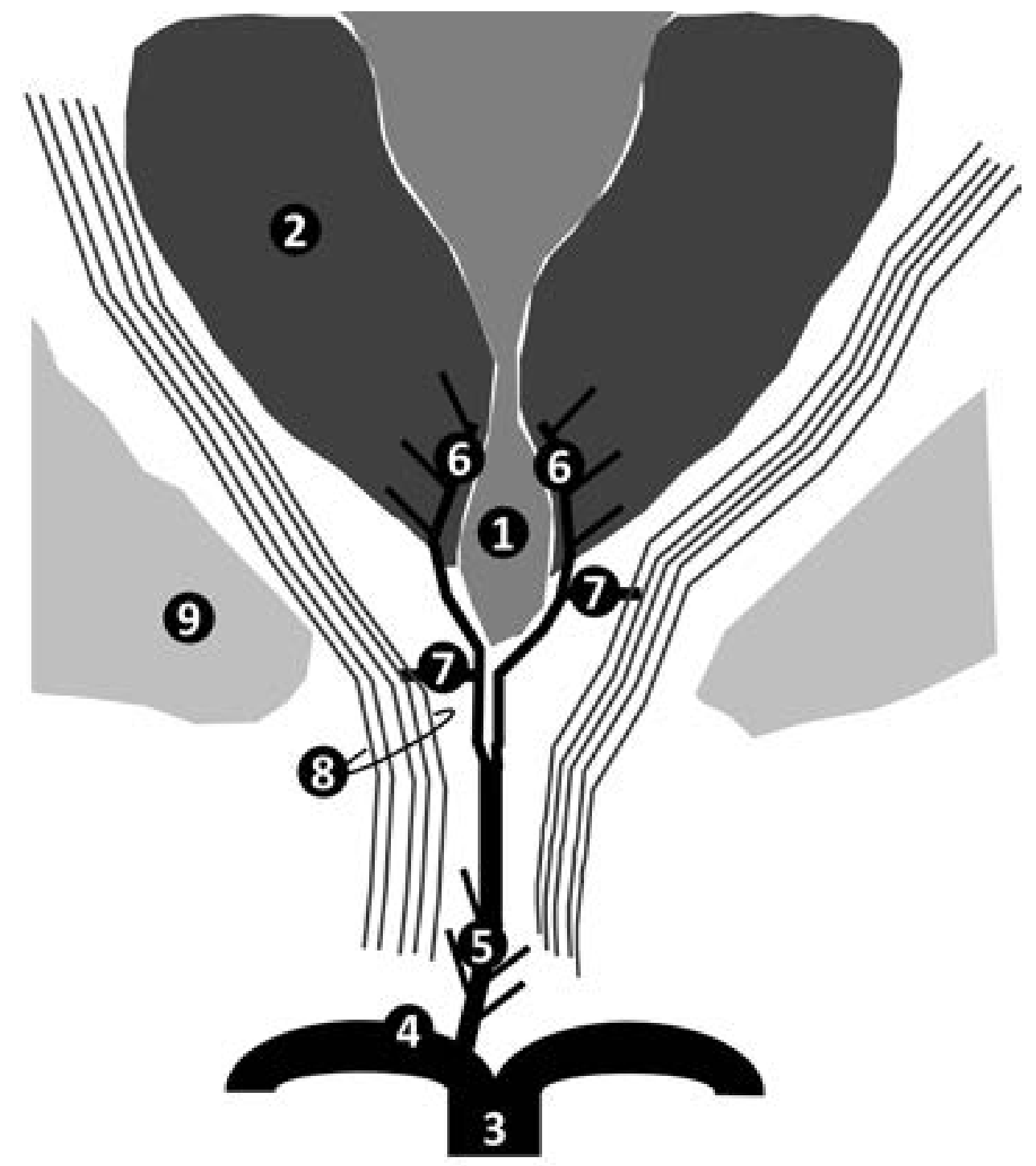

\section{Discussion}

The thalamus is a complex structure formed by nuclei that integrate sensory, motor, and behavioral signals of the cerebral cortex with other pathways. Although there are significant variations and overlaps, this diencephalic large gray matter is supplied by four arteries: three derived from the vertebrobasilar system (paramedian thalamo-subthalamic, thalamogeniculate, and posterior choroidal arteries) and one derived from the posterior communicating artery (polar artery). The paramedian arteries are the most variable when we evaluate number, size, and territorial contribution to the thalamus. ${ }^{4,5}$

Percheron described three possible variations involving the paramedian thalamic-mesencephalic arterial supply. The most common variation is small perforating arteries arising from the first segment of the posterior cerebral artery (PCA). The second variant consists in the dependency of an isolated terminal branch nascent in the PCA for the bilateral blood supply of paramedian thalamus and rostral midbrain. Third, perforating arteries arising from a branch bridging the first segments of both PCA. ${ }^{6}$
The second type, also known as the artery of Percheron $(\mathrm{AOP})$, is considered a normal variant. The prevalence varies among different studies ranging from five to thirty percent in different populations. The classic clinical triad of symptoms in the infarction of the AOP is characterized by consciousness impairment, vertical gaze palsy, and cognitive or behavioral disturbances but a great variability of presentations was already described. ${ }^{7}$

Only a few cases of patients with bilateral paramedian thalamic infarction who develop acute pseudobulbar palsy have been reported in the literature. We identified two cases after a review of the English-language published literature and we compared them with the present case (Table 1). ${ }^{2,38}$ To the authors' knowledge, the reported cases presented other clinical syndromes associated with the pseudobulbar symptoms. In this way, the present case is the first to report isolated pseudobulbar palsy following infarction of Percheron's artery. A literature search was performed in Embase, Google Scholar, Lilacs, Medline, Scielo, and ScienceDirect, using a set of terms that included the thalamus, thalamic stroke, stroke, and abducens palsy.

African Health Sciences, Vol 21 Issue 1, March, 2021 
In the cases of Table 1, all the subjects had acute pseudobulbar palsy but two of them also presented other clinical syndromes at the same time. The study of $\mathrm{Ka}$ racostas et al presented an individual with mild right arm paresis, which is commonly associated with PBP due to extend lesions affecting the upper motor neuron pathway. ${ }^{3}$ In the second study, the subject had cerebellar signs and bilateral upward gaze palsy, which suggests that the infarction also compromised the midbrain; although the authors reported that the mesencephalon was not damaged providing an axial image in fluid-attenuated inversion recovery. ${ }^{2}$ However, only coronal and mainly sagittal neuroimaging are able to clearly visualize the midbrain structures. ${ }^{9}$

Any lesion in the corticobulbar tract can lead to the clinical manifestation of PBP characterized by dysarthria, dysphagia and nasal tuning speech. In this way, we hypothesized that the PBP may have occurred in the subjects of Table 1 because of the existence of vascular territory variations in the perforating arteries that arise from the AOP (Figure 2).,5,7 The posterior limb of internal capsule contains part of the corticospinal, cerebellar and pontine pathways. ${ }^{10,11}$ In fact, diffusion tensor imaging and voltage stimulation variation studies suggested that fronto-ponto-cerebellar fibers are located medially to the corticospinal fibers. ${ }^{12,13}$ In addition, some patients with AOP may have perforating branches throughout their passage from the midbrain to the thalamus. Thus, pseudobulbar, pyramidal, and cerebellar signs could occur in a Percheron's artery infarction. Moreover, the corticobulbar tract is probably the most common to be affected, which could explain the occurrence of the isolated PBP in only one report. ${ }^{7}$

Karacostas et al and Lee et al proposed a different pathophysiological mechanism to this presentation. ${ }^{2,3}$ The ventrolateral nucleus of thalamus has connections with $^{4,6}$, and face cortical areas. Therefore, they proposed that the bilateral lesions in these nuclei could interrupt the thalamocortical projections to the face, resulting in acute pseudobulbar palsy via diaschisis. ${ }^{14}$ Furthermore, Lee et al hypothesized that the oculomotor symptoms occurred because of a lesion affecting the anteroventral nuclei; however, this structure is supplied by the tuberothalamic branch that arises from the middle third of the posterior communicating artery so only large thalamic damage would lead to all these clinical manifestations. ${ }^{4}$ 


\begin{tabular}{|c|c|c|c|c|}
\hline \multicolumn{2}{|l|}{ References } & Karacostas et al & Lee et al & Present \\
\hline \multicolumn{2}{|l|}{ Country } & 1994 & 2016 & 2019 \\
\hline \multicolumn{2}{|l|}{ Year } & Greece & Korea & Brazil \\
\hline \multicolumn{2}{|l|}{ Age $(y) / \operatorname{Sex}$} & $28 / \mathrm{F}$ & $61 / \mathrm{M}$ & $70 / \mathrm{F}$ \\
\hline \multicolumn{2}{|l|}{ Initial symptoms } & $\begin{array}{l}\text { Dysarthria, dysphagia, } \\
\text { hypernasal voice and } \\
\text { mild right arm paresis }\end{array}$ & $\begin{array}{l}\text { Sudden-onset dysarthria } \\
\text { and dysphagia without } \\
\text { motor damage }\end{array}$ & $\begin{array}{l}\text { Difficult articulation of } \\
\text { speech }\end{array}$ \\
\hline \multicolumn{2}{|c|}{$\begin{array}{l}\text { Comorbidities and medications } \\
\text { in use }\end{array}$} & $\begin{array}{l}\text { Contraceptives and } \\
\text { smoking }\end{array}$ & $\begin{array}{l}\text { Alcoholic, hypertension, } \\
\text { diabetes mellitus }\end{array}$ & None \\
\hline \multirow[t]{8}{*}{$\begin{array}{c}\text { Acute } \\
\text { pseudobulbar } \\
\text { palsy } \\
\text { characteristics }\end{array}$} & $\begin{array}{l}\text { Neurological } \\
\text { exam }\end{array}$ & - & $\begin{array}{l}\text { Mild cognition impairment, } \\
\text { upward gaze } \\
\text { limitation, dropped soft } \\
\text { palate, dysarthric, hypernas } \\
\text { al voice, slow tongue } \\
\text { movements, dysmetria in } \\
\text { upper limbs }\end{array}$ & $\begin{array}{l}\text { Dysarthria, hypernasal } \\
\text { voice, dropped soft } \\
\text { palate, slow tongue } \\
\text { movements }\end{array}$ \\
\hline & $\begin{array}{l}\text { Thurel classi } \\
\text { fication }^{8}\end{array}$ & Pontine & $\begin{array}{l}\text { Cortical with ataxia and } \\
\text { cognitive impairment } \\
\text { probably due to alcoholism }\end{array}$ & Cortical \\
\hline & \begin{tabular}{|l|} 
Facio, phary \\
ngo, \\
and glosso \\
masticatory \\
Diplegia \\
\end{tabular} & Yes & Yes & Yes \\
\hline & $\begin{array}{l}\text { Automatic } \\
\text { voluntary } \\
\text { dissociation } \\
\end{array}$ & Yes & Yes & Yes \\
\hline & $\begin{array}{l}\text { Pyramidal } \\
\text { signs } \\
\end{array}$ & Yes & No & No \\
\hline & $\begin{array}{l}\text { Emotional } \\
\text { lability }\end{array}$ & NR & NR & No \\
\hline & $\begin{array}{l}\text { Intellectual } \\
\text { impairment }\end{array}$ & NR & Yes & No \\
\hline & $\begin{array}{l}\text { Cerebellar } \\
\text { signs }\end{array}$ & NR & Yes & No \\
\hline \multicolumn{2}{|l|}{ Neuroimaging } & MRI & $\mathrm{CT}, \mathrm{MRI}, \mathrm{CTA}$ & CT, MRI, CTA \\
\hline \multicolumn{2}{|l|}{$\mathrm{CT}$, MRI findings } & $\begin{array}{l}\text { Bilateral isolated } \\
\text { thalamic infarcts }\end{array}$ & $\begin{array}{l}\text { Lesion limited to the } \\
\text { thalamus }\end{array}$ & $\begin{array}{l}\text { Bilateral thalamic with } \\
\text { extension to midbrain }\end{array}$ \\
\hline \multicolumn{2}{|l|}{ CTA findings } & - & Artery of Percheron & Artery of Percheron \\
\hline \multicolumn{2}{|l|}{ Follow-up } & - & $\begin{array}{l}31 \text { days, patient } \\
\text { tolerate dysphagia diets } \\
2 \& 3 \text {, moderate dysarthria, } \\
50 \% \text { intelligible speech }\end{array}$ & $\begin{array}{l}\text { Patient was referred. } \\
\text { The follow-up was lost. }\end{array}$ \\
\hline
\end{tabular}

\section{References}

1. Besson G, Bogousslavsky J, Regli F, Maeder P. Acute pseudobulbar or suprabulbar palsy. Archives of Neurology. 1991;48(5):501-507.

2. Lee HY, Kim MJ, Kim B-R, Koh S-E, Lee I-S, Lee J. Acute pseudobulbar palsy after bilateral paramedian thalamic infarction: a case report. Annals of Rebabilitation Medicine. 2016;40(4):751.

3. Karacostas D, Artemis N, Giannopoulos S, Milonas I, Bogousslavsky J. Bilateral thalamic infarcts presenting as acute pseudobulbar palsy. Functional Neurology. 1994;9(5):265-268. 
4. Schmahmann JD. Vascular syndromes of the thalamus. Stroke. 2003;34(9):2264-2278.

5. Lazzaro NA, Wright B, Castillo M, et al. Artery of percheron infarction: imaging patterns and clinical spectrum. American Journal of Neuroradiology. 2010;31(7):12831289.

6. Matheus MG, Castillo M. Imaging of acute bilateral paramedian thalamic and mesencephalic infarcts. American Journal of Neuroradiology. 2003;24(10):2005-2008.

7. Arauz A, Patiño-Rodríguez HM, Vargas-González JC, et al. Clinical spectrum of artery of percheron infarct: Clinical-radiological correlations. Journal of Stroke and Cerebrovascular Diseases. 2014;23(5):1083-1088.

8. Thurel R. Les pseudo-bulbaires: étude clinique et anatomo-pathologique: Travail du service du Professeur Georges Guillain, Clinique des maladies du système nerveux (Hospice de la Salpêtrière), G. Doin; 1929.

9. Pullicino P, Lincoff N, Truax B. Abnormal vergence with upper brainstem infarcts: pseudoabducens palsy. Neurology. 2000;55(3):352-358.

10. Ross ED. Localization of the pyramidal tract in the internal capsule by whole brain dissection. Neurology. 1980;30(1):59-59.

11. Kapina V, Sztajzel R, Momjian-Mayor I. Isolated hemiataxia of the cerebellar type after a small internal capsular infarct. Cerebrovascular Diseases. 2008;25(6):594. 12. Nicastro N, Ghika J, Pollak P, Horvath J. Pseudobulbar palsy due to deep-brain stimulation of the thalamic ventral intermediate nuclei. Clinical Neurology and Neurosurgery. 2015;133:61.

13. Kamali A, Kramer LA, Frye RE, Butler IJ, Hasan KM. Diffusion tensor tractography of the human brain cortico-ponto-cerebellar pathways: A quantitative preliminary study. Journal of Magnetic Resonance Imaging. 2010;32(4):809-817.

14. Feeney DM, Baron J-C. Diaschisis. Stroke. 1986;17(5):817-830. 